\title{
Locked and Tied: Locking Chain and Change Of Problems
}

\author{
Kartini $^{1}$, Alfiah Khoirunisa ${ }^{2}$, Raihan ${ }^{3}$ \\ Department of Information System ${ }^{1}$, Master of Information Technology ${ }^{2}$, \\ Department of Faculty Science and Technology ${ }^{3}$ \\ University Of Raharja ${ }^{1,2,3}$ \\ Jl. Jenderal Sudirman No.40, RT.002/RW.006, Cikokol, Kec. Tangerang, Kota Tangerang, \\ Banten 15117, Indonesia ${ }^{1,2,3}$ \\ e-mail: kartini@esaunggul.ac.id ${ }^{1}$, alfiah@raharia.info $^{2}$, raihan.raihan@raharia.info ${ }^{3}$
}

To cite this document:

Kartini, Khoirunisa, A., \& Raihan. (2021). Locked And Tied: Locking Chain And Change Of

Problems. IAIC Transactions on Sustainable Digital Innovation (ITSDI), 3(1), 18-27.

DOI: https://doi.org/10.34306/itsdi.v3i1.500

\begin{abstract}
Blockchains are typically named as democratisation technologies, however ever, their relationship with the law and general democratic establishments remains uncertain. First, it compares blockchain technology with the broader theory of transparency. Second, it examines the link between transparency and democracy, and asks how blockchain technology mediates these relationships. Finally, it studies blockchain however technology affects specific manifestations of transparency and freedom of information. The conclusion of this text is that the relationship between transparency and democratic ideals is complex, controversial, and extremely contextual; the "democratized" technical transparency embedded within the blockchain will simply be evidenced in its application. It's undemocratic. while not considering the political gatekeepers and also the legal, social, and cultural desires that support these goals, blockchain technology cannot bring home the bacon the broader goals of transparency.
\end{abstract}

Keywords: Blockchain, Supply chain, Transparency

\section{INTRODUCTION}

"Code is law". Main provocation is as necessary these days because it was once the Code was 1st issued in 1999. This can be the core of the blockchain. Wright associated American state Filippi stated: "[a] Blockchain technology is widespread, and a centralized government may lose the flexibility to manage and form the activities of various individuals with on the market means". Others are a lot skeptical. Atzori brought up the "global unsettled society" that supported the blockchain as "the story of an equal society based on the blockchain". Between these 2 extremes, "the core issue isn't a way to regulate blockchains, however however they regulate blockchains. They will supplement, supplement or replace the applying of laws". We tend to believe that the blockchain itself isn't a balm or poison. On the contrary, the distinction between medication associated with poison lies within the dosage; the final word impact of the blockchain is not solely mirrored in its inherent properties, however conjointly in its application. Let' take the thought of blockchain as a clear technology as an example[1]. Tapscots believes that "through sensible contracts. [c] firms can arrange relationships with complete transparency". wished for clinical research, company governance and real estate. Even the Canadian government is finding out the likelihood of victimisation of Ethereum to increase transparency. Blockchain as a technology clearly has nice potential, however provided that we tend to don't underestimate its potential human, social and democratic risks, will we totally utilize its benefits? Will blockchain offer "transparency"? Who is it appropriate for? Transparent? 


\section{TRANSPARENCY AND "WORD PROCESSING"}

Leading blockchain and legal scholar Angela Volch believes that "the unstable vocabulary [blockchain] is said to however regulators understand, discuss, and ultimately regulate (or unregulated) technology or its use". The wordbook "even extends to the idea of blockchain itself[2]. "Blockchain technology" may be a somewhat arguable term; though some individuals use it to hide all distributed ledger technologies, differents limit it to being Bitcoin And Ethereum and other cryptocurrency-based distributed ledger technologies. Though there's no unified definition for blockchain technology protocols, the aim of this document is understood as "a distributed ledger that maintains a growing list of public records.

These records are protected by secret writing and can not be tampered with and verified. a part of the matter The definition of blockchain technology stems from the actual fact that at the essential level, blockchain technology distributes dealings ledgers among multiple computers (nodes), every node runs code checks And perpetually copy the most recent copy of the ledger and method it in interconnected blocks; however, before the transaction occurs, it is encrypted and should be verified in line with the blockchain agreement mechanism[3] Then the confirmed transaction is other to the zone Blockchain; the higher than blocks can not be deleted without dynamic the blockchain rules (forking).

Though there are differing types of agreement mechanisms, the idea of consensus mechanisms is crucial to the riotous potential of blockchain technology in documents. Blockchain dealingss aren't certified by a trusty establishment; in fact, there's no legal or different institution to verify the blockchain, however the formula on that the consensus mechanism is trusted. This can be the power of such a "weak" system to verify and verify transaction (such as write and execute) records. Contract, property registration and transfer, trust and property management, and management of identity rights while not the need for fallible and dear intervention by trusty non-public or institutional authorities, even as most authors claim that blockchain may be a group action As stressed in technology.

A vision is a vision within which arithmetic and agreement mechanisms are accustomed cut back (or even eliminate) the requirement for human intermediaries, thereby increasing the access and autonomy of every participant. it's believed that the blockchain is clear as a result of the verification of transactions by mathematicians instead of humans is also less important. However, Walch believes that technical language, just like the statement that a consensus mechanism determines whether or not a system is "unreliable", is obscure at best. Uncertainty regarding the importance of this basic block:

- Terminology: amendment the language to avoid negative associations, such as: B. Bitcoin on the Silk Road.

- Technological changes: There are many alternative blockchain technologies, every with its own characteristics and capabilities.

- Communication between domains: blockChain technology and connected communication problems are extremely interdisciplinary.

- business turning point: vocabulary changes with marketing.

- Correction of inaccuracies: disputes concerning terminology accuracy (such as "miners") have junction rectifier to (some people) it's typically accepted that additional correct expressions (such as "validators").

so as to verify that blockchain technology is basically "transparent", it is necessary to rigorously examine the which means of transparency and underneath what circumstances. The statement that the blockchain is actually clear is predicated on many characteristics of the technology:

- a minimum of in unlicensed blockchains, each node will use the registry.

- The final ledger (in theory) is immutable, contains a fully machine-controlled audit trail, and every dealing has a timestamp.

- Blockchain Disintermediation means (theoretically) no human or establishment intervening in transactions within the chain.

But notwithstanding these claims are believed to be true, this doesn't essentially mean that the blockchain is "transparent", a minimum of not Associate in Nursing exceedingly|in a very\} democratic sense. This can be partially as a result of "transparency" itself could be a 
"dangerous vocabulary", subject to identical intensive references and knowledge domain uncertainty as "unreliability". In fact, long before Satoshi Nakamoto' white book gave birth to Bitcoin and blockchain, the difficulty of "transparency" wasn't resolved. Transparency plays a task at totally different levels, and there are different theoretical assumptions supported the role it plays. within the literature on organization management, transparency is known as an structure theory term; within the literature on body law, political science, and archives theory, transparency is said to democratic theory; however, most models capture human factorssuch as understanding, Trust, friendliness and learning-these aspects all show that transparency could be a social and technological challenge. Schnackenberg and Tomlinson outlined transparency because the "perceived quality of knowledge that the sender intends to provide" and joined it to trust.

Following the tradition of structure governance, Schnackenberg and Tomlinson target the trust of stakeholders and therefore the dependableness of the organization-nevertheless, these ideas play a very important role in the transparency of democratic theories[4]. In the field of structure management, director conjointly identified that "the logic of transparency is especially supported the premise that additional (and more precise) understanding of alternatives can improve learning and control, thereby increasing productivity. The impact of transparency on what's observed, not simply on the audience, Bernstein has developed a transparency and confidentiality model that reflects the conscience of other audiences. need for confidentiality[5][6]. Refusing to produce records that may be accustomed track them:

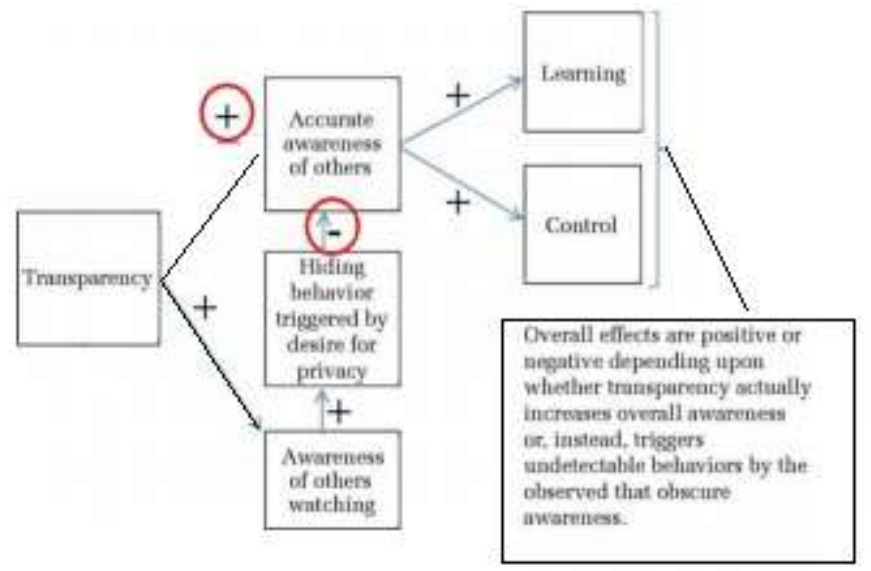

Vacarro projected a transparency theory (2006) relating to the moral problems with introducing info and communication technology (ICT) into business organizations. The Vacarro model aims to supply a way to "determine potential ethical problems arising from the introduction and use of ICT in [business] operations" $(2006,248)$. what's less obvious from the previous model is that it ought to be an inside and external (two-stage) model $(2006,248)$. though the model appears simple, Vacarro believes that transparency "includes dynamic social processes [full of the complexity, interdependence, and dynamics of individual, collective, and social variables concerned in these processes"[7]. 


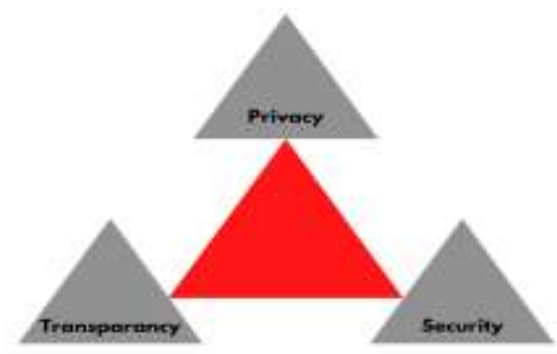

The model shown below by Janssen and van den Hoven tries to capture the link between complexness and transparency within the context of huge open connection information (in bold) for e-government [7].

As Fenster emphasized, models like Janssen and van den Hoven contain some democratic theoretical assumptions that a priori show that "transparency and confidentiality are necessary and necessary social and democratic values." offer info to the public, voters and their participation in the democratic process". His model additionally emphasizes the central role of law (legal and political tools) in our understanding of transparency[8]. However, once blockchain technology is bestowed as "transparent" technology, the purpose is that even the only "transparency" model as a democratic worth emphasizes dynamic and humane processes and concepts. Therefore, we tend to advocate characteristics between technological transparency-technical solutions create information accessible And/or accessibility-and democratic transparency, that is, the perfect of knowledge accessibility, accessibility, and potency to serve additional social goals. together with politicians' responsibilities and citizens' self-efficacy. No reference And support the transparency of laws and different state institutions. As Werbach said, "The notion that each one on-line communities can with success enforce their rules in spite of government will sway be as dangerous because the early days of the Internet. Within the Arab Spring and also the Iranian Revolution in 2018, it became clear that technology alone couldn't deliver democratic values. Technology is clear once allowable by legal, social and cultural forces.

\section{TRANSPARENCY, YES. WHAT IS THE USE?}

If technical transparency alone isn't enough to support democratic ideals, ought to a broader sort of system transparency be developed, and if so, how? Hansen, Christensen, and Flyverbohm make a case for that "all comes in fashionable society typically assume that transparency can effectively guide individual and collective behavior to realize desired results". Janssen and van den Hoven clearly outlined transparency and privacy between one another and also the wider social structure: "Transparency should make sure that state actions and choices may be tracked, whereas confidentiality must ensure that voters aren't controlled and may freely categorical their opinions." Transparency is a necessary balance and watching mechanism to make sure the graceful functioning of a democratic society." Some initiatives, together with the Open knowledge Initiative, Freedom of info/The Right to vary Laws and Law Sun, are supported transparency as a responsibility or a minimum of transparency as a "proethical condition that permits or restricts alternative ethical principles or practices", including the responsibleness system Zarski delineated transparency as "a change in obligatory info equality concerning funding." "Improve efficiency, increase efficiency, and ensure a good democratic process" Lemieux and Trapnell mentioned the role of the correct to Information (RTI) law achieving government transparency, arguing that transparency is vital to responsibleness: "Transparency is that the key to holding the govt accountable. In addition, we tend to perceive that transparency depends on a key component of access: residents of a rustic have the correct to access info created and maintained by their government and institutions"[9]. 
Window ultimately rejected transparency as a in theory and much phantasmagorical concept[10][11]. It totally explained however transparency ought to operate as a officialdom mechanism for public participation and national accountability in a very democratic system: [Transparency] chiefly operates within the monotonous world of jurisprudence ("freedom of information" and "right to know", etc.), and its laws and paperwork increase transparency by obligatory revelation of presidency info. The exalting principle of transparency conjointly applies to political and social theory, wherever it is a basic component of democratic participation and responsibleness a rustic that produces itself visible is so additional democratic, more responsible, and more effective[12][13]. Transparency promotes and strengthens this series of events.

As Fox said: "Transparency should guarantee accountability". In turn, accountability ensures that the system remains democratic as a result of they're responsible to citizens. in a very sense, it's clear because it provides access to information that may be wont to hold actors accountable, thereby achieving democratization. However, even from the best models and definitions planned therefore far, transparency involves higher access to information. Hosseini et al. proposed a "transparency vary" in Exploring Transparency in needs Development, during which the accessibility of knowledge is barely the third step; in his model, the very best range of transparency gains is that the ability to act on information. Accessibility doesn't guarantee the flexibility to act[14][15]. For example, mythical being Nissenbaum wrote that our current "notification and choice system" for data protection management, websites or applications provides notifications concerning the utilization of user data and permits them to opt-out, that creates a "transparency paradox" which gives Notifications with enough information to create a very up on call provide the general public with an excessive amount of information to waste time reading or understanding. During this case, the data is available-at tier of transparency-in the sense that a possible user will read the info process pointers that apply to the user once he registered. However, with the exception of the binary opt-in/opt-out option, \{this is|this is often|this may be\} impossible; users cannot hash out higher data protection clauses or management their data at a granular level.Access that can't be updated can be clear as a result of it makes the information visible, however doesn't essentially democratize it. As Ananny and Crawford explain, "[If] transparency does not have a big impact, then transparency ideas may lose their purpose. when they become additional transparent, more general knowledge can result in more cynicism, it's going to even lead to wider corruption"

In addition, more and more scientists are asking whether or not "transparency" may be emphasised through its metaphoric nature and their hypothesis "includes a higher understanding of the interior workings of the system than familiar To be "correctly regulated and accountable" is so the proper mechanism to carry any system accountable. In fact, "[full transparency will cause plenty of harm. while not understanding why a part of the system should be exposed, transparency threatens confidentiality and prevents honest conversations. A discussion area wherever folks and teams get along to debate problems with common concern and reach agreement once possible", that is consultation the muse of democracy. Transparency, which prevents honest discussions, akin to concerning public records that ought to be accounted for by the courts however employed by non-public companies. ladies collect data to compile subject registers ultimately destroying instead of supporting Democracy. Turilli and Floridi imply that "transparency of knowledge relating to the information disclosed isn't essential". They have an \{ethical\} impact as a result of the data disclosed is virtuously neutral", that transparency itself is not a moral principle, however a "moral", "facilitating" or "destructive" factor. If the disclosed information interferes with ethical principles, it represents Associate in Nursing unethical condition". Therefore, the democratic worth of transparency depends on the context and implementation. As Fox explained, "Transparency mobilizes the ability of shame, but unashamed folks may be shielded from public exposure. Fairness [16] the foremost relevant queries are: what kind of transparency ends up in what responsibility and what beneath what conditions? ". 


\section{4. "TRANSPARENCY" IN ACTION: FREEDOM OF INFORMATION}

So far, this document has shown that transparency isn't solely a theoretical concept, however additionally the fundamental principle of a series of actions taken by organizations and governments. This speech act relies on reliable records. The register should be reliable and valid. To be reliable, the record must be created by a knowledgeable author, and "the content [16] fully and accurately represents [17] the very fact to be proven". Therefore, the responsibleness of the register "depends on the atmosphere within which the [register] is established; unreliable records cannot become reliable". If "it could be a document claiming to [have no] any tampering, replacement or tampering", then the record is authentic, blockchain technology, equivalent to registers, is basically a technology for recording records; though their coding fixity is to confirm the believability of records, they need not taken any measures to ensure the responsibleness of records, or maybe records needed for democratic transparency.

Throughout this investigation, we tend to saw proof of the observe of "oral government", that was distributed orally and there was no record. FIPPA doesn't need recording of those actions. No documentation required. the govt. will effectively avoid data speech act and public review of the explanations and reasons for his or her actions. The shortage of documentation weakens the power of citizens, journalists, and therefore the public to grasp the explanation for state actions on specific topics[18][19][20].

The blockchain solution doesn't give an answer for the govt. or alternative participants to refuse to make a registration. Notwithstanding the info record or data exceeds the data that originally appeared within the chain, there's nothing in the chain itself that may forestall distrust of untrusted data records. several blockchain solutions use off-chain storage for varied reasons, equivalent to adapting to out-of-date data. System, off-chain storage or government restrictions. Records created and keep offline are still vulnerable to all the responsibleness issues that existed before the introduction of the blockchain: "The integrity of the registration is warranted by the shape and order of its creation", if the info record is from the start Untrustworthy, then the authentication of the data record on the blockchain won't modification its form and/or creation method to create the data record trustworthy. when coding within the blockchain, the error report continues to be choked with errors. to confirm democratic transparency, the records came from FOI requests should be reliable; during this regard, blockchain solutions give virtually no blockchain ledger (except, once necessary, transfer their own tokens themselves), and are subject to registration "The quality or validity of the data"[21].

The presently designed blockchain technology additionally cannot store "file links," a network of relationships that link records to alternative records taking part within the same operation (Lemieux and Sporny, 2017). it's almost not possible to grasp the actions and events proven by the record; a file link must be created to stay the record in context. In addition, responses to FOI queries (usually written by non-experts and infrequently while not archive links) could consume longer and resources. Conversely, increasing the quantity of personnel and resources to satisfy $\mathrm{FOI}$ requests at intervals legal and sensible deadlines creates larger opacity. Journalists who often use FOI queries to get the data they have have an expert responsibility to speak that information in a very clear manner. And timely scale back the damage to the underprivileged party. If it's tough for FOI officers to search out response records in a blockchain-based system as a result of such systems didn't ab initio associate the record with its context or its creator, the system won't be able to win the purpose of democracy and transparency as a result of the data can not be quickly obtained If the role of blockchain transparency within the social technical knowledge and communication system is understood, then blockchain transparency can solely be as effective as democratic transparency.

When all, each blockchain answer used for FOI coverage records must be non-public and accessible. For example, several public records subject to FOI additionally contain in person specifiable information (PII) that has to be protected. B. Use offline storage or encoding and use zero-knowledge proofs. However, these selections involve trade-offs that 
must be supported system requirements. though blockchain can give some authenticity, offchain storage systems still face identical persistence challenges as always. Zero-knowledge testing is immature. Correct personal data may also have an effect on the effectiveness of freedom of data law as a transparency mechanism. per current specifications, FOI queries will be performed on processed data records. If personal data is usually transferred to the blockchain, FOI officers can forcibly argue that they ought to keep relevant records in accordance with the private knowledge Protection Act as a result of they can not be manipulated. The balance between data protection and transparency in blockchain solutions, particularly in solutions geared toward promoting democratic transparency, is Associate in Nursing open topic.At best, blockchain will improve the difficulty of human transparency; folks can (and will) build knowledge entry errors or refuse to require notes, thereby touching transparency and accountability.

\section{BIAS OF BLOCKCHAIN}

Therefore, once developing blockchain solutions that support transparency, we tend to should raise ourselves, who the system ought to provide, what quite transparency, what responsibilities, and underneath what conditions. In addition, such a style needs over simply taking advantage of the blockchain. Technology, however you would like to contemplate the biases that these selections bring. exploitation any new technology, it's tough to search out some structural distortions immediately. For example, some distortions of the blockchain is also concerning its immutability. immutableness is one amongst the characteristics that create blockchain technology transparent, but immutability has totally different values in different communities. In fact, in several cases, volatility is very valued, equivalent to the proper to erasure. Forgotten"), it's enclosed within the EU' case law and therefore the General information Protection Regulation (GDPR). it's hardly begun to be underneath stood from the immutableness of blockchain technology, and can without doubt still be developed in RGPD Effective. though the GDPR applies to European resident data used or processed in these jurisdictions, this right doesn't presently exist under Canadian or U.S. law. lawfully binding deletions in immutable solutions need a mixture of various ideas and transparency goals Balance between: Maintaining the immutability of data in the chain is "transparent", as is that the right to manage the individuals concerned within the record in Associate in Nursing accessible and comprehendible way. Even if transparency is seen as an absolute benefit, it should be weighed against different products. The context during which the answer is employed is critical.

As mentioned above, several laws, equivalent to the proper to information/freedom of data law and therefore the solar power law, are expressly supported the principle of transparency. However, these laws explicitly acknowledge the requirement for variability (for example, through wording), and exception clauses that limit revealing for varied reasons (including national security and privacy) play a crucial role within the style and implementation of such laws. If necessary, they'll be abused. "Exceptions, as well as exceptions for the protection of privacy and national security interests, is also abused-used to cover or get pleasure from unfair property interests-rather than to shield personal rights or the general public interest.". In their case, Fang, Graham, and Weill discovered to the u. s. that the implementation of the transparency law depends on the intentions and attitudes of the individuals and establishments that really enforce the law: the president's leadership continues to be crucial to making an atmosphere of openness, formulation or confidentiality [20] Unilateral measures of the chief branch, sometimes taken while not public debate, conjointly show what proportion discretion officers have in promoting or limiting public access to info. In fact, the author points out, "The U.S. Department of Justice has begun to develop a policy [21] to support the agency's actions to keep up confidentiality within the presence of a "strong" legal basis for "retaining information". Confidentiality is one amongst these principles, however storing information on a confidential basis-including information that's essential to protective the rights or interests of the public-can jeopardize transparency, but in fact it doesn't there's no increase in confidentiality, as a result of during this case, case confidentiality is simply 
Associate in Nursing excuse to cover information. the moral problems with getting information, particularly the transparency of accountability, are after all not restricted to the blockchain system; however, in areas designed and used for transparency once employing a blockchain system, it's vital to contemplate the impact of technology and its biases.

\section{CONCLUSION}

Blockchain technology has nice potential and might amendment the manner we have a tendency to conduct business in our daily lives, as well as government business. However, blockchain capabilities alone aren't enough to originate positive social and legal changes. Once applied to the blockchain, terms resembling "transparency" or "democracy" ought to be closely understood. The important "blockchain revolution" can return from the fusion of regulative forces, that should be viewed with caution and targeted on interdisciplinary, that specialize in exposing the assumptions behind the broad claims about the blockchain. The last word impact of blockchain on governance and regulatory systems isn't solely owing to its inherent properties, however additionally owing to its implementation. "Establishing rules, regulations, incentives, and technical design for a well-functioning community [by Lessig' four regulators] may be a terribly tough topic". Blockchain is simply one among these four forces, and can't deliver the goods its full potential alone.

\section{ACKNOWLEDGMENTS}

With high enthusiasm and motivation to work on a journal entitled "Blockchain Technology as a Media for Sharing Information that Generates User Access Rights and Incentives" Thank you to University of Raharja and also Alphabet Incubator who have fully supported this research. So that participation in this research is able to expand knowledge for myself and for other communities, especially for the world of digitization.

\section{References}

[1] Moriarty, K. M. (2020). References. In Transforming Information Security (pp. 199-214). Emerald Publishing Limited. https://doi.org/10.1108/978-1-83909-928-120201009

[2] Rahardja, U., Aini, Q., Ariessanti, H. D., \& Khoirunisa, A. (2018). Pengaruh Gamifikasi pada iDu (iLearning Education) dalam Meningkatkan Motivasi Belajar Mahasiswa. Nusantara Journal of Computers and its Applications, 3(2).

[3] Rahardja, U., Handayani, I., \& Ningrum, A. A. (2018). Pemanfaatan Sistem iMe Berbasis WordPress sebagai Official Site RCEP pada Perguruan Tinggi. Creative Information Technology Journal, 4(3), 207-219.

[4] Ayvaz, S., \& Cetin, S. C. (2019). Witness of Things. International Journal of Intelligent Unmanned Systems, 7(2), 72-87. https://doi.org/10.1108/IJIUS-05-2018-0011

[5] Aini, Q., Graha, Y. I., \& Zuliana, S. R. (2017). Penerapan Absensi QRCode Mahasiswa Bimbingan Belajar pada Website berbasis YII Framework. Sisfotenika, 7(2), 207-218.

[6] Siegfried, N., Rosenthal, T., \& Benlian, A. (2020). Blockchain and the Industrial Internet of Things. Journal of Enterprise Information Management, ahead-of-p(ahead-of-print). https://doi.org/10.1108/JEIM-06-2018-0140

[7] Turner, A. B., McCombie, S., \& Uhlmann, A. J. (2019). A target-centric intelligence approach to WannaCry 2.0. Journal of Money Laundering Control, 22(4), 646-665. https://doi.org/10.1108/JMLC-01-2019-0005 
[8] Lin, J., Shen, Z., Miao, C., \& Liu, S. (2017). Using blockchain to build trusted LoRaWAN sharing server. International Journal of Crowd Science, 1(3), 270-280. https://doi.org/10.1108/lJCS-08-2017-0010

[9] Sinha, D., \& Roy Chowdhury, S. (2021). Blockchain-based smart contract for international business - a framework. Journal of Global Operations and Strategic Sourcing, 14(1), 224-260. https://doi.org/10.1108/JGOSS-06-2020-0031

[10] Rana, R. L., Tricase, C., \& De Cesare, L. (2021). Blockchain technology for a sustainable agri-food supply chain. British Food Journal, ahead-of-p(ahead-of-print). https://doi.org/10.1108/BFJ-09-2020-0832

[11] Sousa, P. R., Resende, J. S., Martins, R., \& Antunes, L. (2020). The case for blockchain in loT identity management. Journal of Enterprise Information Management, ahead-ofp(ahead-of-print). https://doi.org/10.1108/JEIM-07-2018-0148

[12] Kant, N. (2021). Blockchain: a strategic resource to attain and sustain competitive advantage. International Journal of Innovation Science, ahead-of-print(ahead-of-print). https://doi.org/10.1108/IJIS-07-2020-0094

[13] Oh, S.-C., Kim, M.-S., Park, Y., Roh, G.-T., \& Lee, C.-W. (2017). Implementation of blockchain-based energy trading system. Asia Pacific Journal of Innovation and Entrepreneurship, 11(3), 322-334. https://doi.org/10.1108/APJIE-12-2017-037

[14] George, R. P., Peterson, B. L., Yaros, O., Beam, D. L., Dibbell, J. M., \& Moore, R. C. (2019). Blockchain for business. Journal of Investment Compliance, 20(1), 17-21. https://doi.org/10.1108/JOIC-01-2019-0001

[15] Aini, Q., Handayani, I., \& Seto, C. A. (2015). Content Management System Zpreneur in Support of Entrepreneurship llearning at Perguruan Tinggi Raharja. Creative Communication and Innovative Technology Journal, 8(3), 233-245.

[16] Rahardja, U., Aini, Q., \& Sartika, D. (2015). Build A Business To Customer Online Store Using Airzone Content Management System. Creative Communication and Innovative Technology Journal, 8(2), 112-122.

[17] Sousa, P. R., Resende, J. S., Martins, R., \& Antunes, L. (2020). The case for blockchain in loT identity management. Journal of Enterprise Information Management, ahead-ofp(ahead-of-print). https://doi.org/10.1108/JEIM-07-2018-0148

[18] Untung, R., Handayani, I., \& Pahad, B. A. Pemanfaatan Rinfoform Sebagai Media Update Artikel Pada iRan. Jurnal CSRID, 8(3).

[19] Xue, X., Dou, J., \& Shang, Y. (2021). Blockchain-driven supply chain decentralized operations - information sharing perspective. Business Process Management Journal, 27(1), 184-203. https://doi.org/10.1108/BPMJ-12-2019-0518 
[20] Xie, P., Chen, Q., Qu, P., Fan, J., \& Tang, Z. (2020). Research on financial platform of railway freight supply chain based on blockchain. Smart and Resilient Transport, 2(2), 69-84. https://doi.org/10.1108/SRT-09-2020-0007

[21] Rahardja, U., Aini, Q., \& Khoirunisa, A. (2018). The Effect of Rinfogroups as a Discussion Media in Student Learning Motivation. Aptisi Transactions On Management, 2(1), 79-88. 